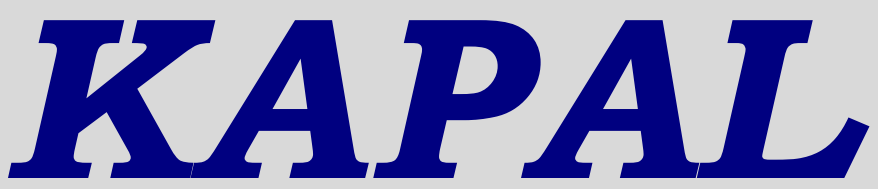

\title{
Desain Kapal Keruk Perairan Dangkal Menggunakan Bucket Elevator
}

\author{
I Putu Sindhu Asmara ${ }^{\left.1)^{*}\right)}$, Hartono Yudo ${ }^{2)}$ \\ ${ }^{1)}$ Jurusan Teknik Bangunan Kapal, Politeknik Perkapalan Negeri Surabaya \\ Jl. Teknik Kimia, Kampus ITS, Sukolilo, Indonesia 60111 \\ ${ }^{2)}$ Departemen Teknik Perkapalan, Universitas Diponegoro \\ Jl. Prof. Soedarto, SH, Kampus Undip Tembalang, Semarang, Indonesia 50275
}

diajukan pada : 22/08/19 direvisi pada :05/09/19 diterima pada :07/10/19

\begin{abstract}
Abstrak
Pengerukan sungai di kota-kota besar biasanya dilakukan dengan menggunakan excavator yang dipasang di atas ponton. Metode ini memiliki kelemahan, yaiu: terbatasnya jarak jangkauan excavator untuk membuang material hasil pengerukan ke tepi sungai. Artikel ini berisikan desain kapal keruk sungai dengan metode pengerukan menggunakan kapal katamaran yang dilengkapi dengan kontainer penampung lumpur sehingga lebar sungai tidak lagi menjadi batasan. Kapal dilengkapi dengan bucket elevator pada bagian buritan kapal yang berfungsi untuk melakukan pengerukan dan berfungsi ganda sebagai propulsi kapal dengan memanfaatkan gaya dorong yang diakibatkan oleh sentakan antara bucket dan dasar perairan. Kebutuhan displacement kapal telah dihitung berdasarkan berat bucket elevator, berat kontainer dan berat konstruksi kapal. Perhitungan hidrostatik dan hambatan kapal dilakukan menggunakan Software MaxSurf dan divalidasi menggunakan pengujian tahanan kapal. Perhitungan bucket elevator divalidasi dengan uji coba pengerukan oleh prototipe kapal dengan skala 1:4. Kapal keruk katamaran ini memiliki displacement 6,972 ton dan mampu menampung muatan lumpur sampai dengan 2,668 ton dengan kecepatan laju hanya 1,7 knot untuk menjaga agar pengerukan terjadi secara merata. Kapal ini sangat sesuai digunakan sebagai kapal keruk sungai yang beroperasi secara rutin untuk memelihara tingkat kedalaman sungai.
\end{abstract}

Copyright @ 2019, KAPAL, pISSN:1829-8370, eISSN : 2301-9069

Kata Kunci : Kapal keruk, Katamaran, Perairan dangkal, Bucket elevator

\section{PENDAHULAN}

Sejak jaman kerajaan Majapahit sampai dengan masa pendudukan Belanda di Indonesia, sungai-sungai di beberapa kota di Indonesia difungsikan sebagai prasarana transportasi. Sayang sekali, pada saat ini sungai-sungai tersebut menjadi sangat dangkal dan tidak lagi dapat dilalui kapal. Pendangkalan sungai menyebabkan aliran sungai tidak lancar dan daya tampung air menjadi sangat terbatas. Hal ini merupakan salah satu penyebab terjadinya banjir selain akibat semakin sempitnya hutan yang berfungsi untuk

*) Penulis Korespondensi :

Email : putusindhu@ppns.ac.id menahan air.

Selama ini pengerukan sungai di perkotaan dilakukan dengan menggunakan alat berat excavator yang dipasang di atas ponton, seperti pada Gambar 1 [1]. Excavator dengan karakteristiknya yang berat memerlukan ponton yang relatif besar untuk mampu mendukung beratnya excavator. Selain itu, dalam operasionalnya olah gerak excavator di atas ponton sangat sulit sehingga jangkauan keruk sangat terbatas. Hasil kerukan excavator umumnya dibuang di pinggir sungai. Banyaknya kandungan air pada buangan hasil kerukan sangat menggangu lingkungan di sekitar sungai. Daerah aliran sungai yang dipadati oleh pemukiman 
menambah permasalahaan, yaitu: semakin sulitnya melakukan pengerukan yang selama ini dilaksanakan dengan menggunakan excavator.

Terbatasnya kedalaman sungai dan berat jenis lumpur yang relatif besar merupakan dua faktor utama yang merupakan kendala dalam perancangan kapal keruk. Kapal keruk menggunakan bucket yang ada saat ini dibuat untuk melakukan pengerukan dengan kedalaman $8 \mathrm{~m}$ sampai $30 \mathrm{~m}$ [2], seperti ditunjukkan pada Gambar 2. Proses pembongkaran hasil kerukan dari ruang muat memerlukan peralatan tambahan yang beratnya akan sangat berpengaruh pada besarnya kapal untuk menyediakan gaya apung yang memadai.

Sejauh ini informasi yang dihasilkan masih terbatas pada pemilihan alat keruk, alternatif metode bongkar muat dan stabilitas kapal. Banyak informasi yang masih belum tersedia untuk mewujudkan rancangan kapal keruk di perairan dangkal, seperti pemanfaatan serba guna kapal keruk dengan rancangan ruang muat dan alat keruk yang dapat dilepas, konstruksi kapal katamaran dengan material ringan, serta pengaruh arus yang terjadi akibat pengerukan terhadap gerakan kapal. Kapal keruk Kalimas dengan sarat 0,75 m dirancang dengan menggunakan suction dredger [3]. Hasil penelitian ini hanya bisa diterapkan untuk pengerukan pada bagian muara, karena kedalaman sungai Kalimas pada kondisi air surut berkisar antara 0,3-0,7 m.

Pada penelitian ini dilakukan desain, pembuatan dan uji coba prototipe kapal keruk untuk mengetahui apakah kapal keruk menggunakan bucket elevator dapat dioperasikan pada sungai dangkal.

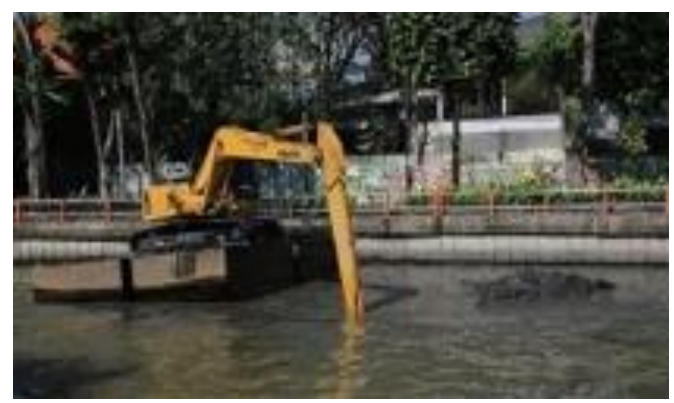

Gambar 1. Excavator - Ponton

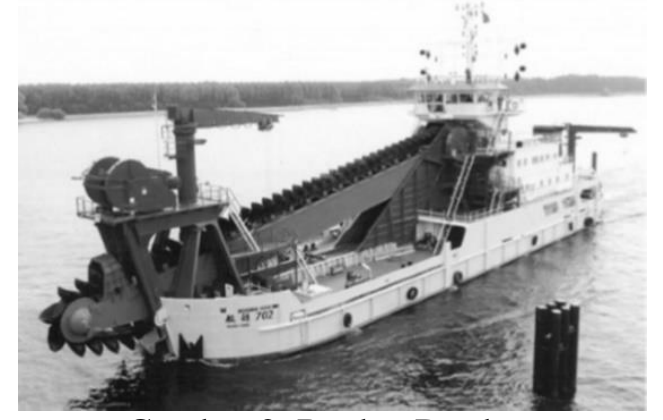

Gambar 2. Bucket Dredger

\section{METODE}

Penelitain ini dilaksanakan dengan metodologi sebagai berikut:

a. Merancang bentuk kapal menggunakan software Maxsurf, dilanjutkan dengan perhitungan hambatan dan hidrostatik

b. Perhitungan hambatan dan kajian teoritis numerik (dengan teknik CFD) pemilihan bentuk katamaran (sebagai alternatif) dari bentuk monohull yang ada selama ini, disertai dengan analisis optimasi jarak lambung

c. Membuat prototipe kapal dengan material GFRP (glassfiber reinforced plastic)

d. Melakukan eksperimental fisik model kapal di kolam uji untuk mengetahui validasi perhitungan tahanan kapal dan besarnya daya penggerak kapal

e. Merancang bucket elevator sebagai alat keruk dan penggerak prototipe kapal

f. Membuat dan memasang bucket elevator pada prototipe kapal keruk

g. Melakukan uji coba operasional prototipe kapal keruk dengan melakukan pengerukan di sungai.

h. Melakukan pengukuran kecepatan kapal selama proses pengerukan.

\subsection{Prototipe Kapal Keruk}

Meskipun telah ada berbagai jenis kapal keruk, prototipe kapal keruk yang akan diteliti mempunyai beberapa kekhususan sebagai berikut:

a. Rancangan kapal katamaran sebagai kapal keruk perairan dangkal merupakan pilihan yang logis untuk mendapatkan ruang muat yang maksimal.

b. Penggunaan bucket elevator sebagai alat keruk memiliki keuntungan yaitu memberikan daya dorong tambahan pada gerakan kapal.

c. Ruang muat yang ditempatkan di antara kedua lambung kapal memiliki keuntungan yaitu dapat dilepas sehingga mempercepat proses bongkar muatan.

Lambung kapal dirancang dengan tipe katamaran sehingga memungkinkan untuk menempatkan ruang muat knock down, bucket elevator dan hopper pada posisi center line. Ada sebuah ruang muat yang bisa dilepas dan dipasang kembali. Penggunaan sistem knock down ini memungkinkan untuk menggeser posisi ruang muat sehingga kondisi trim kapal dapat dikendalikan dengan cara menggeser posisi tersebut kearah memanjang kapal. Sistem ini juga memungkinkan untuk dilakukan penggantian 
panjang elevator yang disesuaikan dengan kedalaman sungai tertentu.

\subsection{Ukuran dan Kecepatan Bucket}

Perancangan bucket elevator dimulai dari penentuan kapasitas pengerukan (Q). Kapasitas pengerukan dapat ditentukan dengan menetapkan berapa lama kapal tersebut membutuhkan waktu $(\mathrm{t})$ untuk memenuhi volume ruangan muatnya $(\mathrm{V})$.

$$
Q=\frac{\rho V}{t}
$$

dimana $\rho$ adalah massa jenis lumpur.

Ukuran alat keruk adalah volume bucket $(\mathrm{Vb})$ dan jarak bucket (pitch). Ukuran pengeruk tergantung dari kapasitas pengerukan (Q) dan kecepatan alat (v).

$$
V_{b}=\frac{Q p}{\rho v \eta}
$$

dimana: $\mathrm{p}$ adalah jarak bucket $(\mathrm{m}), \mathrm{\eta}$ adalah persentase pengisian bucket (\%), Q adalah kapasitas pengerukan (ton/jam), $\mathrm{V}_{\mathrm{b}}$ adalah volume bucket $\left(\mathrm{m}^{3}\right), \rho$ adalah massa jenis lumpur (ton $/ \mathrm{m}^{3}$ ) dan $\mathrm{v}$ adalah kecepatan rantai $(\mathrm{m} / \mathrm{jam})$

Agar material tidak terlempar tepat pada saat bucket mencapai ujung atas elevator maka kecepatan bucket (v) tidak boleh lebih dari $\mathrm{v}_{0}$, dimana $\mathrm{v}_{0}$ adalah kecepatan lumpur pada saat terlempar dari bucket, yaitu sebagai berikut [4].

$$
\begin{aligned}
& v_{0}=\sqrt{g R_{m}} \\
& S=v_{0} t+0,5 g t^{2}
\end{aligned}
$$

dimana: $\mathrm{R}_{\mathrm{m}}$ adalah radius putar rata-rata bucket dalam meter, $\mathrm{S}$ adalah jarak lemparan lumpur, $\mathrm{v}_{0}$ adalah kecepatan lumpur lepas dari bucket $(\mathrm{m} / \mathrm{s})$, $\mathrm{t}$ adalah waktu untuk mencapai penampungan (s) dan g adalah gravitasi bumi $\left(9,81 \mathrm{~m} / \mathrm{s}^{2}\right)$.

\subsection{Lokasi Penelitian}

Prototipe kapal keruk direncanakan untuk dioperasikan di Kalimas Surabaya. Prototipe ini dirancang, dibuat dan diujicobakan di Politeknik Perkapalan Negeri Surabaya. Proses perancangan dilaksanakan di Laboratorium CAD/CAM dengan menggunakan Software MaxSurf dan Ansys, pembuatan prototipe dilalukan di Bengkel Non Metal, sedangkan uji coba prototipe dilaksanakan di Kolam PPNS.
Beberapa metode pengerukan yang ada pada literatur umumnya tidak digunakan pada aliran sungai dangkal, seperti ditunjukkan Gambar 3 sampai dengan Gambar 7 [2,5]. Kapal keruk pada Gambar 3 sampai dengan Gambar 5 menggunakan mekanisma hidrolika dengan pompa penyedot material dasar perairan, sedangkan kapal keruk pada Gambar 6 dan 7 masing-masing menggunakan mekanisme mekanik dengan backhoe dan grab. Pada Gambar 1, lumpur dihisap dan ditampung pada container, sedangkan pada Gambar 4 dan 5 material dihisap dan dialirkan melalui discharge. Pada Gambar 4 material memerlukan penghancuran menggunakan cutter head untuk menghancurkan material sedangkan pada Gambar 5 tidak memerlukan cutter head.

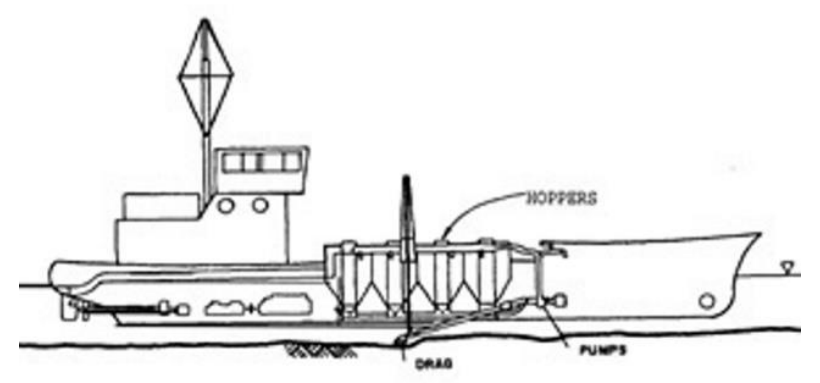

Gambar 3. Kapal Keruk Pompa dengan Propeler

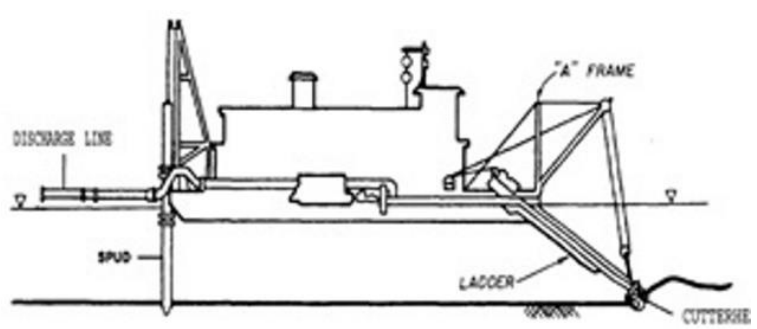

Gambar 4. Kapal Keruk Pompa dengan Spud

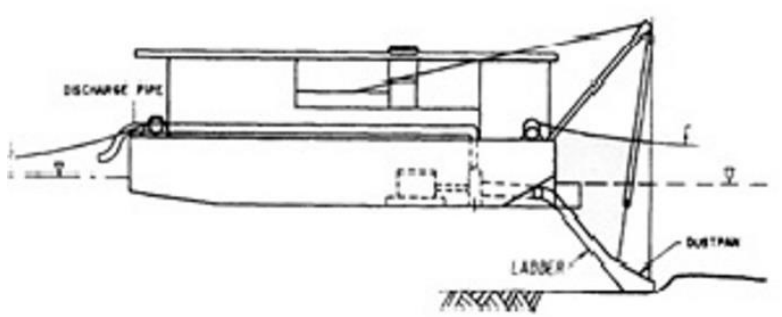

Gambar 5. Kapal Keruk Pompa dengan Tali

\subsection{Metode Pengerukan}




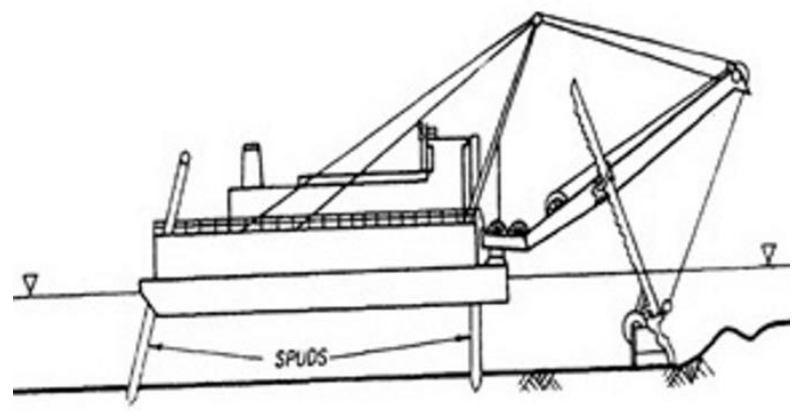

Gambar 6. Kapal Keruk Backhoe dengan Spud

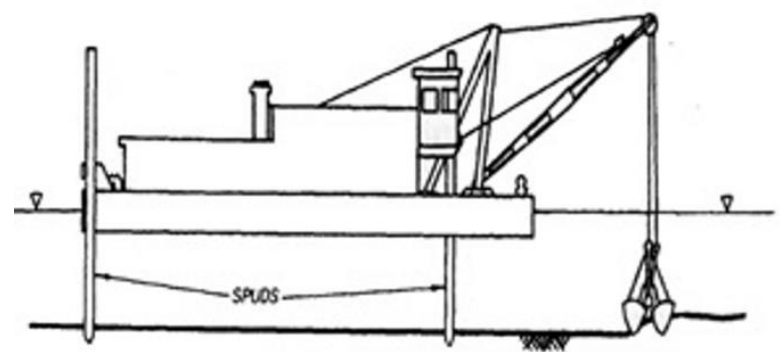

Gambar 7. Kapal Keruk Grab dengan Spud

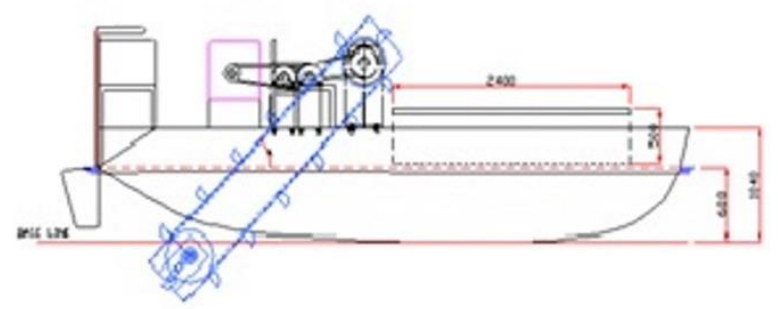

Gambar 8. Kapal Keruk Bucket Elevator

Kelima jenis kapal keruk tersebut juga dapat dibedakan dari penggunaan propeler dan spud untuk memindahkan posisi lambung kapal. Metode pengerukan yang disampaiakn pada artikel ini adalah menggunakan bucket elevator seperti ditunjukkan pada Gambar 8. Kapal ini tidak menggunakan propeler maupun spud karena kapal sudah dipastikan mampu bergerak dengan memanfaatkan gaya dorong yang dihasilkan oleh sentakan bucket dengan dasar sungai. Kapal keruk menggunakan bucket elevator bukan merupakan desain baru. Kapal jenis ini sudah pernah diterapkan [2]. Pada artikel ini diangkat kembali dan disesuaikan untuk diterapkan pada sungai dangkal. Kapal ini juga sudah dikembangkan dan dipatenkan dengan penambahan sirip pada bucket untuk melakukan gerakan ke arah berlawanan [6].

\subsection{Alat dan Bahan}

Prototipe kapal keruk katamaran dibuat dengan skala ukuran 1:4 dan panjang prototipe adalah $1,5 \mathrm{~m}$. Bahan yang digunakan untuk pembangunan lambung prototipe kapal ini adalah glassfiber reinforced plastic (GFRP). Bucket terbuat dari material baja SS 400 yang terpasang pada rantai dan digerakkan oleh motor bakar 0,32 $\mathrm{kW}$.

\section{HASIL DAN PEMBAHASAN}

Survei pada aliran sungai dan muara pelabuhan dilaksanakan pada musim kemarau di sungai Kalimas Surabaya. Survei dilakukan untuk mengetahui kedalaman sungai mulai dari dermaga kapal wisata sampai dengan pelabuhan pelayaran rakyat di muara sungai. Kondisi sungai terdangkal sebesar 0,3 m diukur pada jembatan di sekitar pelabuhan pelayaran rakyat di muara sungai. Pada Gambar 9 terlihat perahu yang sedang mengangkut air tawar untuk kebutuhan kapal pelayaran rakyat yang sedang tambat di muara sungai. Kondisi sungai yang paling dalam diukur pada jembatan dekat dermaga wisata sebesar 0,7 m. Pada Gambar 10 dapat dilihat kapal wisata yang sedang beroperasi di sekitar dermaga wisata. Kondisi sungai seperti tersebut tidak memungkinkan excavator untuk melakukan pengerukan menggunakan ponton di tengah sungai, melainkan hanya mampu dilakukan dari bantaran sungai.

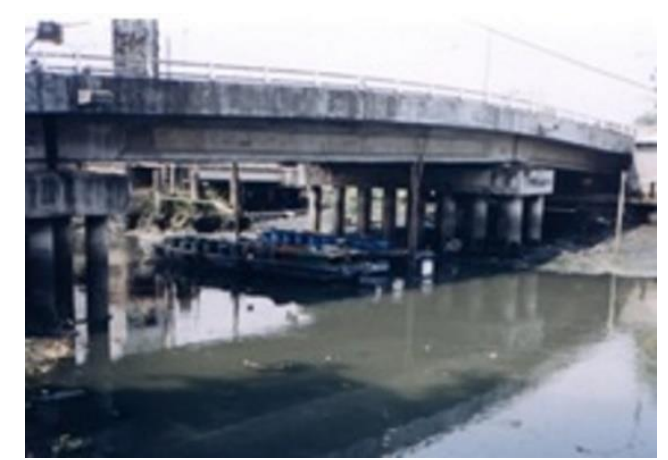

Gambar 9. Kedangkalan di Muara Kali Mas

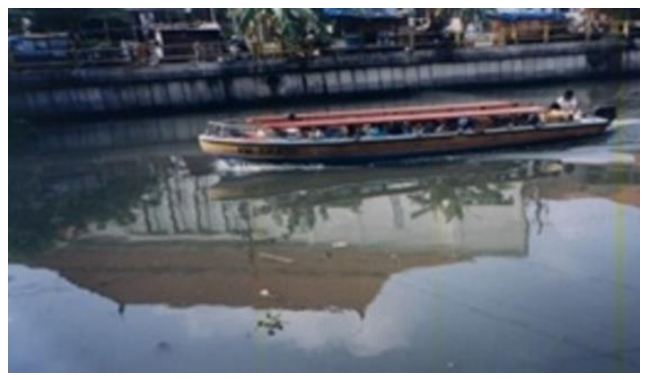

Gambar 10. Kapal Wisata Kali Mas

\subsection{Lambung Katamaran}

Dengan dasar pemikiran bahwa pengerukan direncanakan berawal dari daerah yang paling dalam menuju daerah yang paling dangkal, maka kapal keruk direncanakan memiliki sarat maksimum sebesar $0,7 \mathrm{~m}$. Untuk mendapatkan displacement kapal yang maksimum dan luasan 
geladak yang besar sebagai peletakan alat keruk bucket elevator dan peletakan ruang muat, maka bentuk kapal yang direncanakan adalah kapal katamaran. Melalui perencanaan dengan menggunakan MaxSurf [7], diperoleh bentuk kapal katamaran dengan ukuran utama kapal sebagai berikut: panjang (Lpp) adalah $6 \mathrm{~m}$, lebar lambung (B) adalah 1,2 m, lebar keseluruhan (BOA) adalah 4,2 m, sarat (T) adalah 0,688 $\mathrm{m}$ dan koefisien blok $(\mathrm{Cb})$ adalah 0,728 .
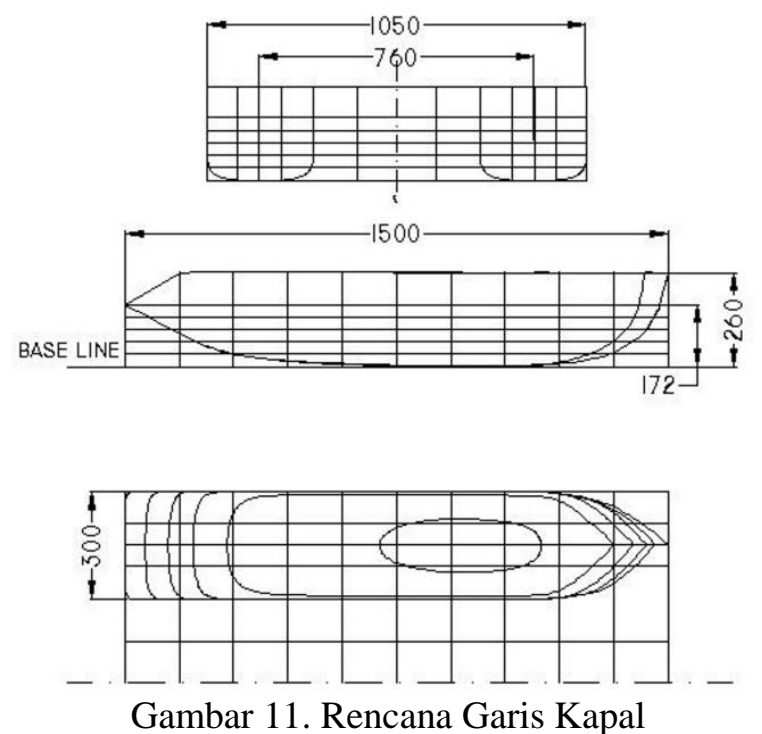

Tabel 1. Karakter Hidrostatik

\begin{tabular}{cll}
\hline No & Item Hidrostatik & Nilai \\
\hline 1 & Displacement $k g$ & 109 \\
2 & Heel degrees & $0^{\circ}$ \\
3 & Draft at FP $m$ & 0.172 \\
4 & Draft at AP $m$ & 0.172 \\
5 & Draft at LCF $m$ & 0.172 \\
6 & Trim $m$ & 0.000 \\
7 & WL Length $m$ & 1.475 \\
8 & WL Beam $m$ & 1.050 \\
9 & Wetted Area $m^{\wedge} 2$ & 1.485 \\
10 & Waterpl. Area $m^{\wedge} 2$ & 0.812 \\
11 & Prismatic Coeff. & 0.767 \\
12 & Block Coeff. & 0.728 \\
13 & Midship Area Coeff. & 0.950 \\
14 & Waterpl. Area Coeff. & 0.933 \\
15 & LCB to Amidsh. $m$ & $0.001 \mathrm{Aft}$ \\
16 & LCF to Amidsh. $m$ & $0.055 \mathrm{Aft}$ \\
17 & KB $m$ & 0.097 \\
18 & KG $m$ & 0.172 \\
19 & BMt $m$ & 1.089 \\
20 & BML $m$ & 1.174 \\
21 & GMt $m$ & 1.014 \\
22 & GML $m$ & 1.099 \\
23 & KMt $m$ & 1.186 \\
24 & KML $m$ & 1.271 \\
25 & TPc Tonne/cm & 0.008 \\
26 & MTc Tonne.m & 0.001 \\
\hline & &
\end{tabular}

Pada Gambar 11 dapat dilihat bentuk garis potongan melintang (body plan), gambar bentuk irisan vertikal kearah memanjang (buttock lines) dan gambar garis air (water lines) prototipe kapal dengan ukuran utama sebagai berikut: $\mathrm{LOA}=1,5$ $\mathrm{m}, \mathrm{BOA}=1,05 \mathrm{~m}, \mathrm{H}=0,26 \mathrm{~m}$, dan $\mathrm{Cb}=0.728$. Displacement kapal tersebut adalah $109 \mathrm{~kg}$ dengan berbagai karakteristik hidrostatik pada sarat penuh $0,172 \mathrm{~m}$, seperti ditunjukkan pada Tabel 1.

Displacement prototipe sebesar $109 \mathrm{~kg}$ mewakili displacement kapal yang sebenarnya sebesar 6,972 ton, yaitu sebesar $4^{3}$ atau 64 kali displacement prototipe. Sarat prototipe sebesar 0,172 m mewakili sarat kapal sebesar 0,688 m, yaitu 4 kali sarat prototipe dan luas garis air, waterplane area (WPA) sebesar $0,812 \mathrm{~m}^{2}$ mewakili $4^{2}$ atau 16 kali WPA prototipe.

\subsection{Tahanan Kapal}

Hasil perhitungan hambatan dan daya penggerak kapal menggunakan Hullspeed menunjukkan bahwa prototipe tersebut membutuhkan daya sebesar 0,2 HP (150 watt) pada kecepatan 3 knot $(1,5 \mathrm{~m} / \mathrm{s})$. Hasil perhitungan ini menunjukkan nilai yang tidak berubah meskipun jarak antar lambung kapal divariasikan. Hal ini menunjukkan bahwa Hullspeed tidak memperhitungkan efek aliran diantara kedua lambung kapal.

Mengingat kompleksnya aliran disekitar lambung kapal, maka total hambatan kapal sangat sulit untuk diprediksikan hanya dengan menggunakan metoda teoritis. Percobaan model masih merupakan data yang paling akurat untuk menentukan performansi kapal. Ciri khas dari hidrodinamika kapal katamaran adalah adanya interaksi aliran diantara kedua lambung. Total hambatan kapal dinyatakan dalam persamaan sebagai berikut [8].

$$
R=0,5 C_{T} \rho v_{m}^{2} S_{w}
$$

dimana: $\mathrm{C}_{\mathrm{T}}$ adalah koefisien hambatan total, $\rho$ adalah masa jenis fluida, $\mathrm{v}_{\mathrm{m}}$ adalah kecepatan kapal dan $S_{w}$ adalah luasan permukaan basah kapal.

Untuk mengetahui validitas hasil hambatan seperti di atas, maka dilakukan pembuatan model kapal katamaran tersebut yang selanjutnya diuji pada towing tank di Laboratorium Hidrodinamika ITS. Pada tahap pengujian prototipe ini kami memvariasikan nilai perbandingan jarak lambung dengan panjang kapal (S/L), yaitu: $20 \%, 30 \%$ dan 40\%. Model kapal ditunjukkan apda Gambar 12 
dan data hasil pengujian adalah seperti terlihat pada Tabel 2.

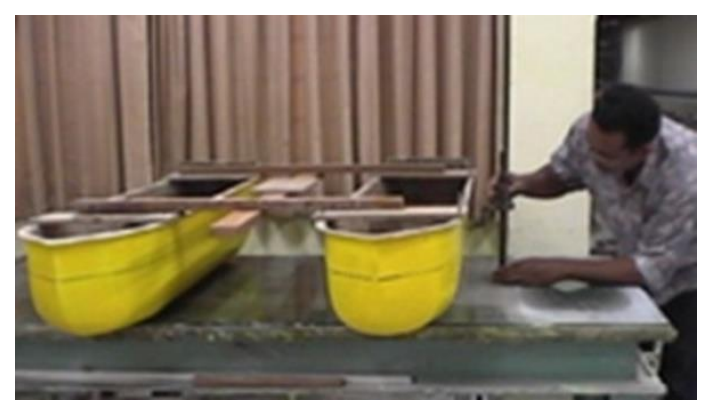

Gambar 12. Model Uji Tahanan Kapal

Tabel 2. Hasil Uji Tahanan Kapal

\begin{tabular}{ccc}
\hline S/L & Kecepatan, $\mathbf{v}(\mathbf{m} / \mathbf{d t})$ & Tahanan, $\mathbf{R}(\mathbf{k g})$ \\
\hline \multirow{3}{*}{$20 \%$} & 0.43062 & 0.0143 \\
& 0.56108 & 0.0684 \\
& 0.68803 & 0.1779 \\
$30 \%$ & 0.19816 & 0.0381 \\
& 0.39801 & 0.2193 \\
& 0.61715 & 0.5219 \\
$40 \%$ & 0.18510 & 0.0348 \\
& 0.58098 & 0.1291 \\
& 0.84512 & 0.4080 \\
\hline
\end{tabular}

Dari ketiga variasi $\mathrm{S} / \mathrm{L}$ tersebut diatas nilai kebutuhan daya dorong yang paling mendekati hasil perhitungan menggunakan Hullspeed adalah kebutuhan daya pada $\mathrm{S} / \mathrm{L}=0,2$ sebesar 186,48 watt dan terdapat perbedaan hasil perhitungan sebesar $19,56 \%$.

Dengan menggunakan persamaan Dubrovsky, maka besarnya koefisien hambatan total model kapal tersebut adalah 2,95E-03, 1.64E-02, dan 8,67E-03 mading masing pada rasio jarak lambung $20 \%, 30 \%$ dan $40 \%$. Ratarata koefisien hambatan total adalah 9,34E-03. Penelitian mengenai koefisien hambatan total kapal katamaran [9], menunjukkan nilai yang mendekati, yaitu 8E-03.

Analisis CFD dilakukan dengan analisis ditekankan terhadap garis air pada posisi sarat air penuh. Pemodelan dilakukan pada badan kapal format katamaran $(\mathrm{S} / \mathrm{L})=20 \%, 030 \%$ dan $40 \%$ sesuai dengan jarak pisah pada uji eksperimental model. Hasil-hasil analisis diperlihatkan pada Tabel 3.

Tabel 3. Hasil Analisis CFD

\begin{tabular}{ccc}
\hline S/L & Tahanan Gesek & Tahanan Total \\
\hline $20 \%$ & 0.060 & 0.096 \\
$30 \%$ & 0.059 & 0.081 \\
$40 \%$ & 0.058 & 0.075 \\
\hline
\end{tabular}

Seperti halnya dengan uji model kapal maka tampak dengan jelas (secara kualitatif) telah terjadi pengurangan gaya hambatan seiring dengan meningkatnya jarak antara lambung kapal.
Jarak terjauh $(\mathrm{S} / \mathrm{L}=40 \%)$ memperlihatkan suatu kondisi dimana interaksi gelombang antara lambung praktis tidak ada, seperti terlihat pada Gambar 13.

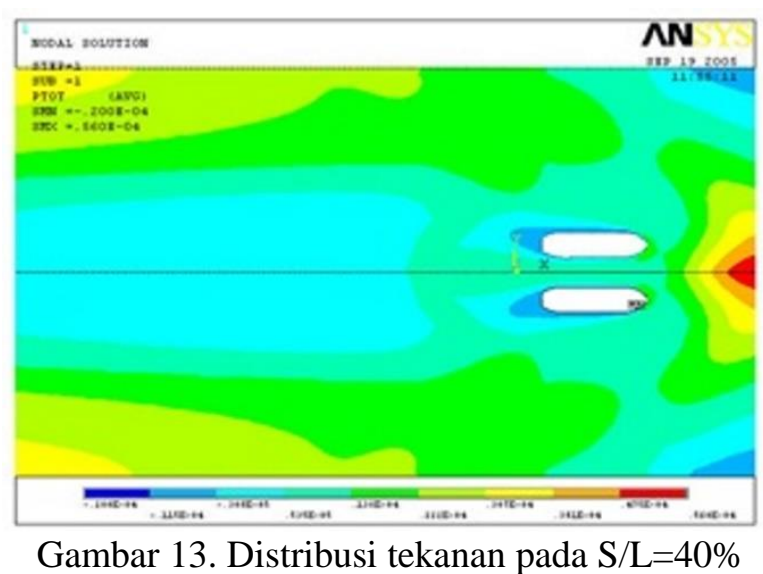

\subsection{Bucket Elevator}

Massa jenis lumpur diukur dengan cara menimbang lumpur yang telah dimasukkan ke dalam kemasan. Data berat lumpur tersebut adalah sebagai berikut:

1. Massa sampel I : 852 gram

2. Massa sampel II : 818 gram

3. Massa sampel III : 830 gram

4. Massa sampel IV : 846 gram

5. Massa sampel V : 846 gram

Rata-rata berat jenis lumpur tesebut adalah sebagai berikut:

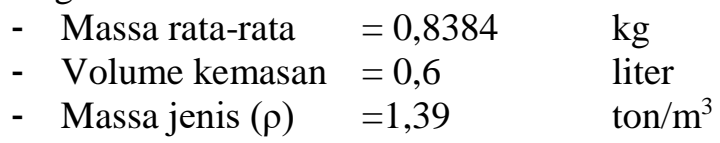

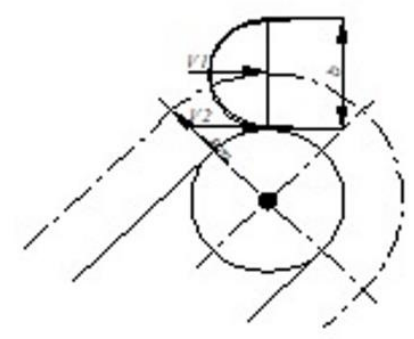

Gambar 14. Model Bucket Elevator

Agar lumpur terlempar tepat pada saat bucket berada pada posisi puncak elevator seperti terlihat pada Gambar 14, maka besarnya gaya sentrifugal haruslah sama dengan berat lumpur pada bucket, sehingga dapat dituliskan dengan persamaan sbb:

$$
m g=\frac{m v_{1}^{2}}{R_{m}}
$$


Dengan demikian maka kecepatan bucket dapat dihitung dengan persamaan sbb:

$$
\begin{aligned}
& v_{1}=\sqrt{g R_{m}} \\
& v_{2}=\frac{R_{s}}{R_{m}} v_{1}
\end{aligned}
$$

dimana : Rm adalah jarak dari sumbu putar ke pusat lumpur, $\mathrm{g}$ dalah percepatan gravitasi dan Rs adalah jari-jari sproacket.

Prototipe ini direncanakan menggunakan sproacket dengan jari-jari $0,065 \mathrm{~m}$, dengan lebar bucket adalah b. maka persamaan di atas menjadi, sebagai berikut.

$$
\begin{aligned}
& v_{1}=\sqrt{g(0,065+b / 2)} \\
& v_{2}=\frac{0,065}{R_{m}} v_{1}
\end{aligned}
$$

Sehingga jumlah putaran sprocket per menit $(\mathrm{N})$ adalah sebagai berikut.

$$
N=\frac{60 v_{2}}{2 R_{S}}
$$

Daya yang diperlukan untuk memutar sproacket dapat dibedakan menjadi 2 (dua) keadaan, yaitu: bucket berada pada posisi di dalam air dan pada posisi mengeruk lumpur.

Daya yang diperlukan oleh bucket elevator pada posisi tidak mengeruk adalah:

$$
P=\frac{2 \pi N T}{60}
$$

dimana: $\mathrm{N}$ adalah jumlah putaran per menit sesuai dengan persamaan 11, dan torsi ( $\mathrm{T}$ adalah sebagai berikut.

$$
\begin{aligned}
T= & \left\{0,065 W_{1}+\left(0,065+\frac{b}{2}\right)\left(W_{2}+\right.\right. \\
& \left.\left.W_{3}\right)\right\} \sin (\alpha)
\end{aligned}
$$

dimana: $\mathrm{W}_{1}$ adalah gaya akibat berat rantai $(\mathrm{N})$, $\mathrm{W}_{2}$ adalah gaya akibat berat bucket $(\mathrm{N}), \mathrm{W}_{3}$ adalah gaya akibat berat air pada bucket $(\mathrm{N})$ dan $\alpha$ adalah kemiringan bucket elevator.

Daya di atas dipergunakan oleh bucket elevator untuk mengangkat air di dalam bucket. Pada saat bucket masuk ke dalam air akan terjadi momentum sebesar:

$$
M=m v
$$

dimana : $m$ adalah massa air yang dipindahkan, vadalah kecepatn air saat terlempar, seperti dihitung dengan persamaan 3 .

Massa air yang dipindahkan dalam satu kali ayunan bucket adalah:

$$
m=\rho_{a} b l s
$$

dimana: $\mathrm{b}$ adalah lebar bucket, 1 adalah panjang bucket, $\mathrm{s}=\pi(0,13+\mathrm{b}) / 2$, yaitu lintasan bucket dalam satu kali putaran sproacket dan $\rho_{\mathrm{a}}$ adalah masa jenis air.

Karena waktu yang diperlukan untuk satu putaran sproacket adalah jarak lintasan dibagi kecepatan maka:

$$
t=\frac{\pi(0,13+b)}{v}
$$

Dengan demikian daya yang digunakan untuk memindahkan air di dalam $\mathrm{n}$ jumlah bucket adalah:

$$
\begin{aligned}
& P_{1}=\frac{n m v^{2}}{t} \\
& P_{1}=n \rho_{a} b l v^{3}
\end{aligned}
$$

Jadi daya yang diperlukan pada posisi tidak mengeruk, yaitu posisi dimana bucket elevator hanya melewati air adalah:

$$
P_{2}=\frac{2 \pi N\left\{0,065 W_{1}+\left(0,065+\frac{b}{2}\right)\left(W_{2}+W_{3}\right)\right\} \sin (\alpha)}{n \rho_{a} b l v^{3}}+
$$

Bucket elevator direncanakan mempunyai panjang 0,84 $\mathrm{m}$, sehingga alat ini akan melakukan pengerukan pada kemiringan $27^{\circ}$ sampai dengan kemiringan $45^{\circ}$.

Pada saat bucket elevator melakukan pengerukan maka daya yang dibutuhkan lebih besar dari pada posisi bucket berada di dalam air saja. Daya tambahan yang dibutuhkan adalah daya untuk mengeruk lumpur dan mengangkat lumpur, sehingga Persamaan-13 menjadi sebagai berikut:

$$
P_{2}=\frac{2 \pi N\left\{0,065 W_{1}+\left(0,065+\frac{b}{2}\right)\left(W_{2}+W_{4}\right)\right\} \sin (\alpha)}{n \rho_{l} b l v^{3}}+
$$

dimana: $\mathrm{W}_{4}$ adalah gaya akibat berat yang diangkut dan $\rho_{1}$ adalah berat jenis lumpur $\left(\mathrm{N} / \mathrm{m}^{3}\right)$.

Daya yang dihitung pada persamaan 20 merupakan daya minimal, sehingga daya di atas perlu ditambahkan sebesar $25 \%$, sebagai daya yang diasumsikan hilang pada bearing dan rantai. 
Pada saat pengerukan bucket elevator harus dijaga agar selalu berada pada posisi seperti pada Gambar 14.

Seperti terlihat pada Gambar 15, sudut kontak antara bucket dengan lumpur adalah $90^{\circ}$. Dengan demikian waktu yang dibutuhkan untuk sekali pengerukan $\left(t_{k}\right)$ adalah seperempat dari waktu untuk satu putaran sproacket.

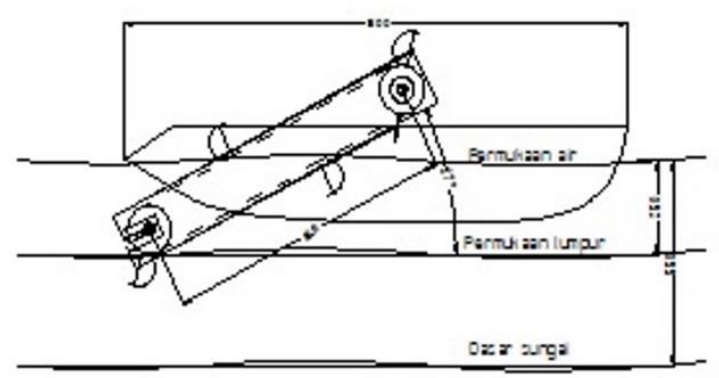

Gambar 14. Kemiringan Bucket Saat Pengerukan

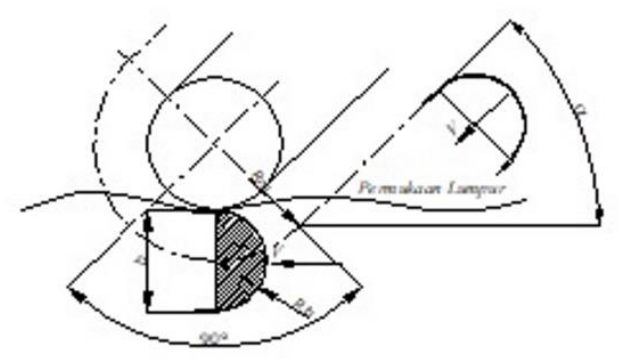

Gambar 15. Posisi Bucket Saat Pengerukan

Jarak horisontal yang dikeruk dalam satu kali kerukan adalah:

$$
S_{k}=2(0,65+b) \sin \left(45^{\circ}\right)
$$

Pada saat yang sama bucket di dalam air juga mengayuh air. Daya ini juga memberikan efek gerakan kapal kearah horisontal, sehingga total daya yang mengakibatkan gerakan kapal kedepan adalah:

$$
P_{k}=0,5 n\left(\rho_{a}+\rho_{l}\right) b l v^{3} \cos (\alpha)
$$

Jika kecepatan kapal pada daya dorong Pk adalah c $(\mathrm{m} / \mathrm{s})$, maka agar efektifitas pengerukan menjadi optimal (100\%), maka kecepatan c haruslah sebesar:

$$
c=\frac{4 v S_{k}}{\pi(0,13+b)}
$$

dan jarak antara bucket adalah:

$$
S_{b}=\frac{0,13 \pi}{4}=0,102 \mathrm{~m}
$$

Panjang bucket elevator, 1 adalah 0,84 m, panjang keliling rantai adalah 2,5 m dan jumlah bucket, $\mathrm{n}$ adalah 12 buah. Bentuk penampan lintang bucket adalah setengah lingkaran degan diameter $b$, sehingga kapasitas pengerukan dari bucket elevator adalah:

$$
\begin{aligned}
& Q=3600 \frac{0,25 n \pi b^{2} v}{2,5} \quad\left(\mathrm{~m}^{3} / \mathrm{h}\right) \\
& Q=360 n \pi b^{2} v \quad\left(\mathrm{~m}^{3} / \mathrm{h}\right)
\end{aligned}
$$

Dari persamaan-persamaan yang telah dijabarkan diatas, dapat disimulasikan beberapa ukuran bucket. Untuk mendapatkan daya dorong sebesar 150 watt maka lebar bucket adalah $60 \mathrm{~mm}$ dan panjang bucket $250 \mathrm{~mm}$. Bila faktor hambatan pada bearing dan rantai diperhitungkan sebesar $25 \%$ maka daya yang dibutuhkan oleh bucket elevator tersebut adalah 323 watt. Jadi dari daya pengerukan sebesar 323 watt, 150 watt diantaranya digunakan untuk mendorong kapal. Kecepatan pengerukan kearah horisontal pada daya dorong 150 watt adalah $1,14 \mathrm{~m} / \mathrm{s}$. Berdasarkan perhitungan dengan menggunakan Hullspeed, dengan daya dorong 150 watt, kapal akan bergerak dengan kecepatan $3 \mathrm{knot}(1,5 \mathrm{~m} / \mathrm{s})$.

Dengan menggunakan persamaan-persamaan tersebut di atas, dapat dihitung waktu yang dibutuhkan oleh satu kali kerukan bucket adalah 0,15 s. Dengan kecepatan $1,5 \mathrm{~m} / \mathrm{s}$ maka jarak yang ditempuh oleh kapal adalah 0,23 m. Jarak horisontal yang dilalui bucket pada saat mengeruk lumpur adalah $0,18 \mathrm{~m}$. Dengan demikian dapat disimpulkan bahwa efektifitas alat keruk ini adalah $0,18: 0,23=76 \%$. Artinya, kalau kapal berjalan $100 \mathrm{~m}$ maka total bagian yang terkeruk sepanjang $76 \mathrm{~m}$. Sedangkan kapasitas pengerukan prototipe bucket elevator tersebut adalah 11,79 $\mathrm{m}^{3} / \mathrm{h}$.

\subsection{Uji Coba Prototipe}

Untuk mengetahui validasi perhitungan efek daya dorong kapal yang diakibatkan oleh alat keruk maka dilakukan percobaan pengerukan. Gambar 16 menunjukkan prototipe kapal yang sedang diuji coba.

Hasil uji coba seperti pada Tabel 4 menunjukkan adanya perbedaan kecepatan kapal antara uji coba dengan perhitungan. Pada saat tidak mengeruk, kecepatan uji coba hanya 34\% dari kecepatan perhitungan. Sedangkan pada saat mengeruk kecepatan kecepatan uji coba hanya $14 \%$ dari kecepatan yang diperhitungkan. 


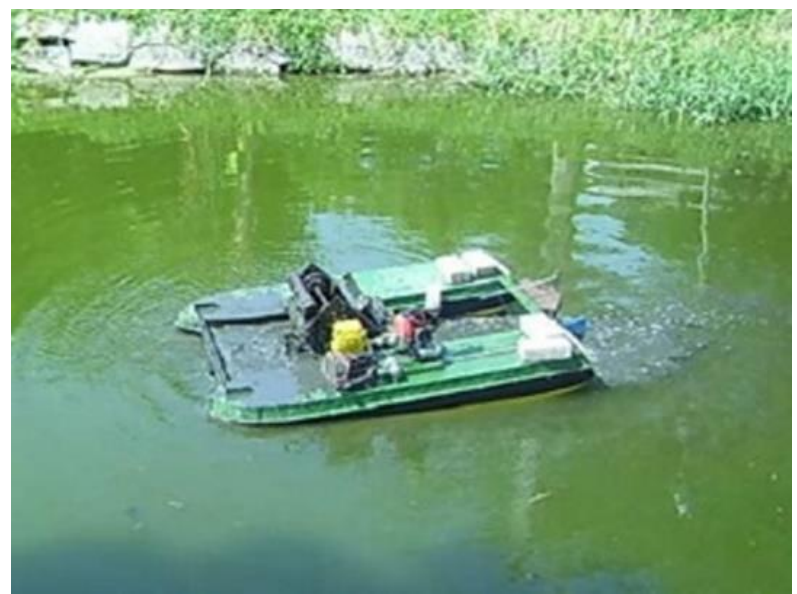

Gambar 16. Uji Coba Pengerukan

Tabel 4. Hasil Uji Coba

\begin{tabular}{ccc}
\hline RPM & Kemiringan & $\begin{array}{c}\text { Kecepatan Rata-Rata } \\
(\mathbf{m} / \mathbf{s})\end{array}$ \\
\hline 97 & $15^{0}$ & 0.49 \\
97 & $45^{0}$ & 0.20 \\
50 & $15^{0}$ & 0.36 \\
\hline
\end{tabular}

Dengan demikian dapat dinyatakan bahwa efisensi penggerak kapal menggunakan kayuhan bucket pada saat tidak mengeruk mencapai $34 \%$, sedangkan pada saat mengeruk hanya mencapai 14\%. Meskipun efisiensi tersebut relatif kecil jika dibandingkan dengan efisensi propeler, tetapi hal ini hanyalah efek samping dari fungsi utamanya sebagai alat keruk.

Dari hasil perhitungan dengan ukuran kapal yang sebenarnya didapatkan bahwa pada kemiringan pengerukan $45^{\circ}$, dibutuhkan daya untuk pengerukan sekitar 11,29 kW. Dengan daya tersebut pengerukan berlangsung dengan lintasan keruk 1,93 meter per detik. Sedangkan efek daya dorong kapal akibat pengerukan adalah sekitar $7,13 \mathrm{~kW}$. Daya dorong tersebut akan menyebabkan kapal bergerak dengan kecepatan sekitar 5 knots $(2,5 \mathrm{~m} / \mathrm{s})$. Berdasarkan uji coba prototipe, kecepatan kapal hanya 34\% dari 2,55 $\mathrm{m} / \mathrm{s}$, yaitu sebesar $0,85 \mathrm{~m} / \mathrm{s}$. Karena kecepatan kapal lebih kecil dari kecepatan lintasan pengerukan maka dapat disimpulkan bahwa pengerukan akan berlangsung tanpa adanya lokasi dasar sungai yang tidak terjangkau oleh bucket elevator.

\subsection{Kapasaitas Muatan}

Bak lumpur direncanakan dapat dipasang dan dilepas sehingga pada saat pembuangan lumpur bak tersebut ikut terangkat ke dalam truk. Hal ini dimaksudkan untuk mempercepat proses bongkar muat. Dengan mempertimbangkan hal tersebut maka bak tersebut direncanakan dibuat dari material baja, sedangkan badan kapal terbuat dari fiberglas agar dapat memperkecil berat kapal kosong (LWT). Agar kapal tidak mengalami trim yang berlebih maka bak tersebut dipasang pada bagian depan kapal dan sebagai pengimbangnya bucket elevator dan kursi operator diletakkan pada bagian belakang kapal, seperti ditampilkan pada Gambar 17.

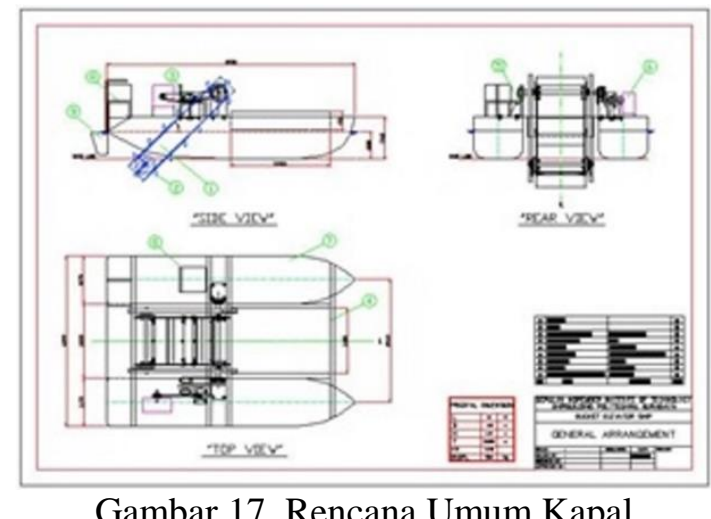

Berdasarkan Lloyd Register of Shipping [10], bila rasio kecepatan dan panjang kapal adalah 2,04, maka:

- Jarak gading adalah $380 \mathrm{~mm}$ (direncanakan jarak gading $300 \mathrm{~mm}$ )

- Berat laminasi kulit sisi adalah: $2,15 \mathrm{~kg} / \mathrm{m}^{2}$

- Berat laminasi geladak adalah: $1,85 \mathrm{~kg} / \mathrm{m}^{2}$

- Berat laminasi kulit alas adalah: $2,65 \mathrm{~kg} / \mathrm{m}^{2}$

- Modulus gading adalah $15 \mathrm{~cm}^{3}$

Balok geladak direncanakan menggunakan profil baja dengan perhitungan pada kondisi bak terpenuhi oleh lumpur adalah sebagai berikut:

- Berat lumpur adalah: 2668,80 kg

- Berat bak lumpur dari pelat adalah: $688 \mathrm{~kg}$

- Momen lentur maksimum yang diterima oleh balok geladak adalah: 302 kg.m

- Momen lentur tersebut ditahan oleh pipa kotak dengan ukuran 120x60x4 mm, dengan berat $285 \mathrm{~kg}$ dan tegangan $85,6 \mathrm{~N} / \mathrm{mm}^{2}$

Gading kapal direncanakan dengan ukuran seperti pada Gambar 18. Modulus gading tersebut sebesar $18,92 \mathrm{~cm}^{3}$.

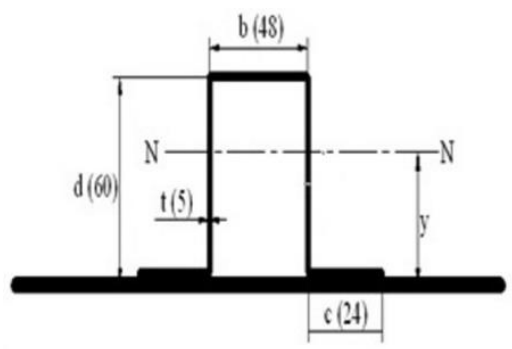

Gambar 18. Ukuran Gading

Semua bagian konstruksi tersebut di atas direncanakan menggunakan lapisan glassfiber reinforced plastic (GFRP) seperti pada Tabel 5. 
Mat dipilih karena sifatnya yang lebih homogen, sedangkan pemilihan woven roving karena membentuk ketebalan laminat yang lebih cepat dan kekuatan serta kekakuan lebih bagus daripada mat [11].

Tabel 5. Layer GFRP

\begin{tabular}{lcc}
\hline Nama Lapisan & $\begin{array}{c}\text { Berat } \\
\left(\mathbf{g} / \mathbf{m}^{\mathbf{2}}\right)\end{array}$ & $\begin{array}{c}\text { Tebal } \\
(\mathbf{~ m m})\end{array}$ \\
\hline Choped Strand Mat & 450 & 0,9 \\
Choped Strand Mat & 450 & 0,9 \\
Woven Roving & 600 & 0,734 \\
Woven Roving & 600 & 0,734 \\
Choped Strand Mat & 450 & 0,9 \\
Choped Strand Mat & 450 & 0,9 \\
Total & $\mathbf{3 0 0 0}$ & $\mathbf{5 , 0 6 8}$ \\
\hline
\end{tabular}

Tabel 6. Berat Kapal

\begin{tabular}{llr}
\hline No. & Item & Berat $(\mathbf{k g})$ \\
\hline 1 & Kulit sisi & 181,48 \\
2 & Kulit geladak & 68,25 \\
3 & Gading & 128,52 \\
4 & Balok geladak & 285,16 \\
5 & Kursi & 20,00 \\
6 & Bucket Elevator & 1690,09 \\
7 & Kemudi & 100,00 \\
8 & Bak lumpur & 687,66 \\
9 & Lumpur & 2668.80 \\
10 & Operator & 150,00 \\
11 & Ballast & 992,04 \\
& Total & $\mathbf{6 . 9 7 2 , 0 0}$ \\
\hline
\end{tabular}

Berat kosntruksi dan komponen kapal keruk adalah seperti pada Tabel 6. Kapasitas muatan pada kapal tersebut sekitar 2,7 ton atau sekitar $38 \%$ dari displacement kapal.

\section{KESIMPULAN}

Bucket dredger bisa diaplikasikan untuk perairan dangkal. Desain kapal keruk katamaran menggunakan bucket elevator dapat dioperasikan tidak hanya untuk kedalaman $8 \mathrm{~m}$ sampai $30 \mathrm{~m}$, tetapi dapat dirancang khusus untuk pengerukan sungai dengan kedalaman $0,7 \mathrm{~m}$. Kapal keruk katamaran dengan panjang $6 \mathrm{~m}$ dan displacement 6,972 ton memiliki kapasitas muatan sebesar 38\% dari displacement kapal. Berat kapal kosong hanya 4,3 ton dan sistem konstruksi yang knock down sangat memungkinkan bagi kapal untuk beroperasi di lingkungan sungai perkotaan. Selain itu, kapal keruk katamaran lebih mudah untuk dimobilisasi bila dibandingkan dengan penggunaan excavator dan ponton.

\section{UCAPAN TERIMA KASIH}

Penulis mengucapkan terima kasih kepada DIKTI atas dukungan dana penelitian, mulai dari program Hibah Bersaing, Hi-Link dan CPPBT sampai dengan dikeluarkannya Paten Kapal Keruk Katamaran Menggunakan Bucket Elevator Bersirip oleh Kemenkumham.

\section{DAFTAR PUSTAKA}

[1] https://news.detik.com/berita-jawa-timur/d3663897/lumpur-hasil-pengerukan-sungaidan-saluran-digunakan-ngurukfasum/komentar. [Diakses 19 Agustus 2019]

[2] W.J.Vlasblom, Design Dredging Equipment, Chapter 6 Bucket (Ladder) Dredger, 2004.

[3] Herijono, B dan Prayitno M.M.E., "Perencanaan Dredger Ship untuk Normalisasi Hilir Sungai Kalimas," Seminar Master, PPNS, 2017.

[4] Renold, Conveyor Chain, Chapter 4 Conveyor Chain Designer Guide, 2014.

[5] US Army Corps of Engineers, Engineering and Design; Dredging and Dredged Material Management, EM 1110-2-5025, Department of the Army, 2015.

[6] Asmara, I.P.S. dan Utama, I.K.A.P., 2017. Kapal Keruk Katamaran yang Dilengkapi dengan Bucket Elevator Bersirip. Kementerian Hukum dan Hak Asasi Manusia Republik Indonesia. Paten. Nomor IDP000045824.

[7] Maxsurf, Maxsurf Pro 7.16 User Manual, Formating Design Pty Ltd, 2002.

[8] V. Dubrovsky and A. Lyakhovitsky, MultiHull Ships, Backbone Publishing Company, USA, 2001.

[9] M. Haase, G. Thomas, G. Davidson, and J. R. Binns, “ Apractical Design Approach including Resistace Prediction for medium Speed Catamarans", Ship Technology Research, 2013 [Online]. DOI:10.1179/str.2013.60.1.001 [Diakses 19 Agustus 2019]

[10] Lloyd Register of Shiping, (1983), Rules and Regulation for Classification of Yatchs and Small Craft, London.

[11] Scott, Robert M., (1996), Fiberglass Boat Design and Construction, 2nd edition, SNAME, New Jersey.O. M. Faltinsen, Hydrodynamics of High-Speed Marine Vehicle, Cambridge: Cambridge University Press, 2005. 